\title{
Mexico Ciudad Segura
}

\author{
Jean Henri Loic Lancelin and Hao Ming Huang
}

\begin{abstract}
Mexico Ciudad Segura (Mexico Safe City) project provides an urban security solution to Mexico City, aiming to improve the operational efficiency of police and inter-agency coordination, better communication with citizens, reduce the crime rates and achieve better safety in the city. The Mexico Ciudad Segura solution is a large and complex "System of Systems" (SOS), comprising of a field layer (Cameras, Automatic Plate Number Recognition, Gun Shot Detectors, Emergency Interphones, Mobile communication equipment for the Police forces) connected to 5 Command and Control (C2) Centers and 2 mobile C2s, under the supervision of a Command, Control, Communications, Computers, and Intelligence (C4I) Center. The Mexico Ciudad Segura has been developed by a consortium including Thales and Telmex the Mexican national telecom operator. Three entities of Thales have been involved in the solution design and development. This presentation provides the background information of the project, including the project schedule, engineering dimensioning parameters, concept and overview of operations, share of works and complexity profiler. It reviews the engineering challenges encountered and Thales' response to the challenges by using iterative development, integration and validation lifecycles in all Thales entities. The solution is deployed successfully in Mexico City and key statistics are shown to demonstrate the benefits to the city.
\end{abstract}

J.H.L. Lancelin $(\bowtie) \cdot$ H.M. Huang

Thales Solutions Asia, 21 Changi North Rise, Singapore 498788, Singapore

e-mail: jean.lancelin@ asia.thalesgroup.com

H.M. Huang

e-mail: haoming.huang@asia.thalesgroup.com

M.-A. Cardin et al. (eds.), Complex Systems Design \& Management Asia, Advances in Intelligent Systems and Computing 426, 